\title{
As implicações do trabalho sobre o corpo humano e o descarte da velhice
}

\author{
The implications of work on the human body and discarding of elderly
}

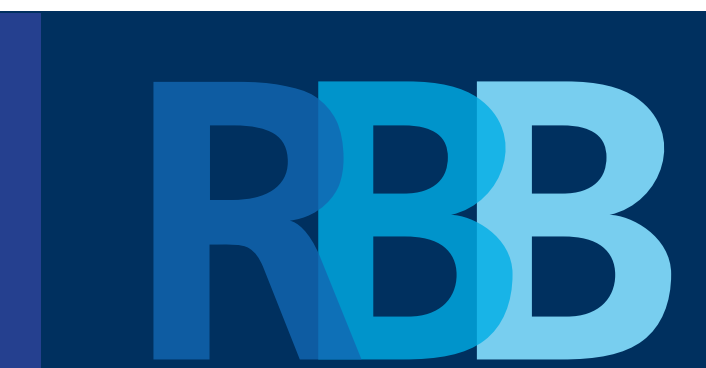

Revista Brasileira de Bioética

\section{Vitor Rafael de Souza Ribeiro}

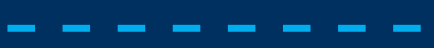

Programa de Pós-Graduação em

Bioética, Pontifícia Universidade Católica do Paraná, Curitiba, PR, Brasil vitor_0506@hotmail.com

\section{Tiago Morales Calve}

- $-2-0-5$

Departamento de Psicologia, Universidade Federal do Paraná, Curitiba, PR, Brasil tiagocalve@gmail.com

\section{Thiago Rocha da Cunha - $-\overline{-}-\overline{-}=$}

Programa de Pós-Graduação em Bioética, Pontifícia Universidade Católica do Paraná, Curitiba, PR, Brasil rocha.thiago@pucpr.br
Resumo: O presente artigo analisa conflitos bioéticos relacionados à descartabilidade da velhice na ordem social capitalista. Orientada por uma pesquisa de tipo teórica e interdisciplinar, a análise relaciona a determinação histórico-social do trabalho e suas implicações na corporeidade e constituição humana - especialmente do corpo envelhecido. Discute que o envelhecimento não deve ser concebido como um processo individual e puramente compreendido por processos cronológicos e/ou biológicos, mas como um fenômeno coletivo atravessado por questões éticas, históricas e políticas. Como conclusão indica a necessidade de uma bioética do envelhecimento capaz de orientar políticas públicas e agendas de pesquisas voltadas à compreensão e intervenção nos conflitos éticos que afetam os trabalhadores envelhecidos, especialmente aqueles que são descartados pelo trabalho na ordem social capitalista.

Palavras-chave: trabalho, corpo, envelhecimento, bioética.

Abstract: The present article analyzes bioethical conflicts related to discarding of elderly in the capitalist social order. Oriented by a theoretical research, this analysis relates the historic-social determination of labor and its implications towards the human corporeity especially the aged body. It also discusses that aging should not be construed as an individual process, purely chronological or biological, but as a collective phenomenon crossed by ethical and political matters. It concludes by the necessity of an elderly bioethics that is able to orientate public policies and research agendas, aiming the comprehension and intervention in ethical conflicts which affects elder workers, especially those discarded by the employment market in the capitalist order.

Keywords: work, body, aging, bioethics. 


\section{Notas introdutórias}

Segundo a Secretaria Especial de Direitos Humanos do Ministério de Justiça e Cidadania (2017), uma em cada nove pessoas no mundo tem 60 anos ou mais. No Brasil, a população idosa totaliza 23,5 milhões de pessoas. Este fenômeno vertiginoso do avançar da idade na contemporaneidade deve ser analisado para além das questões puramente estatísticas e quantitativas. Por isso, o entendimento deste fenômeno à luz do cenário econômico global, à luz dos tensionamentos e conflitos éticos de ordem social, sanitária, clínica e ambiental, faz-se necessário. Dessa forma, temos na bioética uma importante ferramenta interdisciplinar de compreensão e resolução dos conflitos que emergem desse complexo processo humano. A bioética, especialmente nas produções de autores que analisam criticamente o sistema capitalista, tal como Berlinguer (1993) e Garrafa e Porto (2005), propõe a leitura crítica dos problemas coletivos e da reprodução dos modos de vida, denunciando as iniquidades e as injustiças sociais, buscando contribuir com a transformação da realidade como práxis social.

Para tanto, num primeiro momento iremos apresentar a partir da tradição marxista a compreensão da constituição do sujeito a partir de um ponto de vista material, concreto e histórico. Na sequência, apresentaremos a bioética de intervenção como uma ferramenta teórico-prática necessária para o reconhecimento do corpo como parâmetro de intervenção ética. Por fim, iremos analisar o fenômeno da velhice como a expressão clara da descartabilidade do humano sob a lógica de produção capitalista, sendo necessária uma reflexão bioética para o envelhecimento humano.

\section{O trabalho e a constituição do sujeito}

Para a tradição dialética e materialista do conhecimento da realidade, o trabalho é uma categoria central no que se refere à dinâmica da constituição histórico social da humanidade e do sujeito. Um método de análise desta natureza é imprescindível para a reflexão bioética do corpo, uma vez que pela lógica dialética é capaz de superar tradições dicotômicas historicamente presentes no campo das ciências médicas, sociais e humanas, tal com a contraposição excludente entre saúde e doença, normal e patológico, individual e social, novo e velho, corpo e mente, dentre outras. Neste sentido, a categoria corpo será aqui analisada em sua totalidade e concretude, ou seja, pelos intercâmbios do corpo com a natureza e as trocas sociais. A atividade material prática humana é entendida, conforme analisa Leontiev (1978), como uma unidade molecular em que os elementos constituintes da existência humana estão em uma relação de reciprocidade/contradição e movimento. Graças ao trabalho, atividade material prático-intelectual dos seres humanos, é possível a produção e reprodução material 
da vida. "O trabalho é, antes de tudo, um processo entre o homem e a natureza, processo este em que o homem por sua própria ação medeia, regula e controla seu metabolismo com a natureza (Marx, 2015, p.255)".

Assim, o processo de trabalho possui em si uma dimensão ontológica (constituinte do ser), sendo a natureza e o humano pressupostos da produção material, mediados pelos meios de produção e das relações sociais de produção. Ao analisar a história, Marx salienta a existência e a importância da relação material entre homem e o trabalho, desde os primórdios da história, afirmando que:

A fim de se apropriar da matéria natural de forma útil para sua própria vida, ele põe em movimento as forças naturais pertencentes a sua corporeidade: seus braços e pernas, cabeça e mãos. Agindo sobre a natureza externa e modificando-a por meio desse movimento, ele modifica, ao mesmo tempo, sua própria natureza (Marx, 2015, p.255).

Contudo, com o processo de fundação da propriedade privada dos meios de produção, instala-se na história da humanidade a marca da luta de classes sociais. Com o advento da sociedade moderna industrial o trabalho converte-se em força de trabaIho, ou seja, uma mercadoria a ser vendida no mercado de trabalho. Em outras palavras, o operário (pertencente à classe despossuída dos meios de produção) vende a sua força de trabalho ao capitalista (pertencente à classe possuidora dos meios de produção). A questão primordial é que, sob a lógica do trabalho alienado na sociedade capitalista, não há liberdade real para o trabalhador transitar sua atividade de maneira mais plena, tendo impactos na constituição de suas capacidades e habilidades, impactos no seu desenvolvimento, sua corporeidade e saúde.

O lugar que ocupa o trabalhador na sociedade the confere um tipo de constituição própria: fragmentada e unilateral. Realizar uma atividade alienada ao longo da vida, como é o caso do trabalho neste tipo de sociedade, não implica que a constituição humana cesse. Mas que, sob estas circunstâncias, - o trabalho alienado e exploração capitalista - no decorrer da ontogênese deixam marcas nas capacidades, habilidades, interesses, necessidades, motivações e corporeidade.

Feito os devidos esclarecimentos no que se refere a uma perspectiva materialista e dialética de constituição do sujeito, passaremos adiante às considerações acerca da história do capitalismo, suas mudanças nas formas de organização e reprodução, bem como seus impactos na constituição do sujeito. Neste sentido, consolidado o processo de Revolução Industrial na Europa no século XIX, tal como apresentado por Marx e Engels, o início do século XX é marcado por novas mudanças nos modos 
de produção capitalista. Idealizado pelo estadunidense Henry Ford (1863-1947), o modelo - fordista - modificou o processo artesanal de produção de carros e implementou o Sistema Taylor na linha de montagem de automóveis.

O Sistema Taylor consiste em um método científico de administração desenvolvido pelo engenheiro estadunidense Frederick Taylor (1856-1915), que tem como finalidade uma forma de organização do trabalho humano, programando o parcelamento das atividades e tarefas exercidas pelos trabalhadores através da supervisão e do controle dos movimentos laborais e o tempo na execução de cada tarefa. O trabaIhador no sistema Fordista/Taylorista passa a ser apenas um "apêndice do sistema mecânico, ou seja, um corpo morto (Santos, 2009, p.7)".Assim sendo, a totalidade humana (sua existência corporeidade-subjetividade) estão condicionadas sob a lógica da fragmentação.

Não há dúvidas de que a racionalização científica dos meios de produção capitalista promovida pelo Fordismo/Taylorismo elevou exponencialmente a produção dos bens de consumo e o acúmulo de capital. Nesse sentido, Santos (2009) analisa que esta transição se difundiu para todo o sistema produtivo como forma de organização da produção e do trabalho. Havia como base a linha de montagem, a produção em massa, consumismo massificado, controle do tempo e movimentos laborais, produção parcelada, cisão entre planejamento e execução do trabalho e a consequente desqualificação do trabalhador. Sendo a época do surgimento de uma nova institucionalidade não só para garantir a reprodução do capital, mas para manter o capitalismo. Neste período, foi necessário incorporar as massas, ou seja, oferecer aos trabalhadores estabilidade no emprego, direitos previdenciários, saúde, educação etc. O Estado, nesta senda, assume para si a garantia destes direitos civis eximindo inclusive os donos do capital da responsabilidade de manutenção da força de trabalho. Do ponto de vista do sujeito, em detrimento da exploração e desgaste oriundo da exploração do trabalho, há ainda que mínimo,certo amparo via políticas públicas estatais de cunho social.

Com a grande crise na década de 1970, o capitalismo precisa se reformular para garantir sua acumulação e, dessa forma, outro formato de produção é colocado em prática nas indústrias devido à necessidade de transformação exigida pelo capital diante da crise econômica mundial e a consequente queda do lucro. É neste momento instável que, segundo Alban (1999) começa a ser praticado, em larga escala mundial, o método japonês de produção, conhecido como Toyotismo (1948 e 1975). A característica central do toyotismo é de que o trabalhador não podia ser especializado em funções únicas e restritas como no modelo fordista. Ao contrário, essa força 
de trabalho tinha que executar diversas tarefas, desempenhar habilidades e funções em diferentes equipamentos, além da exigência do trabalho em grupo com intuito de mudar e reconfigurar todo o sistema produtivo sempre que necessário. Desta maneira, conforme analisa Alban (1999), nascia a lógica do trabalho "flexível". Do ponto de vista político-ideológico há um conjunto de transformação e reformulações sob a denominação de neoliberalismo. A tese central deste conjunto político ideológico, conforme analisa Fiori (1997) é o mínimo de intervenção estatal na economia e na promoção de políticas públicas de natureza social, bem como a ultra-valorização das liberdades individuais ou, em outros termos, a valorização do (ultra)individualismo.

Com a reestruturação dos modos de produção, a evolução do capitalismo exigiu a formação de um trabalhador supostamente mais participativo, tecnicamente apto as mudanças e aparentemente polivalente. Porém, esta polivalência é vivenciada de forma ambígua, pois trouxe também ao trabalhador uma maior responsabilidade, um autocontrole coercitivo e menor autonomia, ou seja, o trabalhador foi cooptado subjetivamente ao trabalho alienante. Para Lacaz (2000), o trabalho que deveria ser prazeroso, em que deveria ser delegada ao trabalhador uma parte importante da concepção, da inventividade e da capacidade de solucionar problemas, passou a ser tratado apenas como uma nova forma de aumentar a produção.

O impacto dessas reformulações traz sérias consequências sobre a existência (corporeidade/subjetividade) dos trabalhadores, uma vez que se intensificam os níveis de exploração e desgaste oriundos da produção, contudo, com o desmonte das políticas públicas de cunho social, o ônus deste padrão de desgaste fica sob a responsabilidade individual e corporal dos sujeitos. Ou seja, no plano ideológico, os sujeitos são responsabilizados pela condução de sua vida, e por consequência pelo seu processo de envelhecimento, abstraindo-se da constituição humana toda a totalidade histórico-social.

\section{O corpo e a bioética de intervenção}

Segundo Garrafa (2005), a bioética estabeleceu-se no século XX com o intuito de propor novos modelos de integração e interação entre o ser humano e o ambiente que o rodeia. Com o passar dos anos e em contextos diferenciados, as perguntas acerca do tema da bioética tomaram novas direções, criando novos espaços de debate e fomentando novas indagações. Nas últimas décadas, em especial nos países latino-americanos, um dos pontos que vem chamando atenção dos pesquisadores da área diz respeito ao caráter de intervenção prática comprometida com o humanoe com a transformação social. 
Conceitos como empoderamento, libertação e emancipação sustentam os princípios e as motivações da Bioética de Intervenção no debate global (Garrafa, 2005). As persistentes desigualdades sociais que se apresentam nos países periféricos, como o acesso a recursos de subsistência, faz da bioética uma ferramenta de intervenção ética aplicável. A bioética de intervenção atua através da ação social politicamente comprometida em transformar a realidade para afirmar os valores e a dignidade da vida humana como ferramenta de práxis social.

Lins, Vasconcellus e Palacios (2005) afirmam que um dos referenciais da bioética é sua estrutura "multiintertransdisciplinar", sendo embasada por diversas áreas do conhecimento que se entrelaçam e se ligam, promovendo uma análise do objeto de estudo realizado por diferentes vertentes científicas, levando a diversas interpretações sobre o mesmo tema. Sempre contando com o embasamento biotecnocientífico, a bioética não deixa de lado questões a respeito da materialidade social que nos constitui como seres humanos. Reivindica também a pluralidade moral dos indivíduos que deve ser assegurada pelo Estado Democrático de Direito, sempre no sentido de promover um convívio entre os diferentes atores morais de forma pacífica, legitimando a necessidade da utilização de narrativas contemporâneas e concretas como a comunicação, coerência e a argumentação factual para o resultado esperado.

Para Garrafa (2005) a bioética de intervenção surge como uma ferramenta de denúncia e reflexão que parte de países periféricos do Hemisfério Sul, os quais foram colonizados pelos países centrais, deixando marcas profundas e situações persistentes de desigualdade, exploração e opressão nesses locais. Os autores reconhecem que o desenvolvimento e a racionalidade que afloraram durante a Modernidade na Europa esteve diretamente relacionado à conquista e à exploração dos continentes americano e africano, sobretudo da América Latina, ou seja, não haveria a riqueza e o desenvolvimento do norte sem a exploração e apropriação do sul.

A qualidade de vida, os acessos à saúde, à educação, ao trabalho e a busca por equidade nos países centrais se difere em muito da realidade encarada pelos países periféricos, isso não apenas supõe uma diferença de nível de desenvolvimento, mas também um escalonamento de valores entre as vidas. Esse seria, de acordo com Nascimento e Garrafa (2011), um aspecto em comum entre as diferentes formas de colonização, quais sejam econômicas ou aquilo que os autores definem de Colonialidade da vida.

Essa forma de colonização, para Nascimento e Garrafa (2011) é exatamente o processo de criar uma ontologia de vida que autorize a pensar que algumas vidas são 
mais importantes do que outras, fundando assim uma hierarquia, uma casta, uma relação de poder que cria uma justificativa para a dominação, exploração e submissão dos povos periféricos, sob o pretexto de ser esse o caminho para o desenvolvimento econômico mundial. Nas palavras de Nascimento e Garrafa (2011, p.289): "é impossível entender os efeitos, os sentidos, as dinâmicas e as práticas de poder da Modernidade sem entender que ela tem em sua base uma lógica colonial".

Diante do contexto histórico-geográfico, a bioética de intervenção, que surge na América Latina, apresenta a corporeidade humana como marco teórico e conceitual, e as sensações de prazer e dor como indicadores da necessidade bioética dessa intervenção. O reconhecimento do corpo como parâmetro para intervenção ética, para Porto e Garrafa (2005), se dá pelo fato de que o corpo é a manifestação concreta e universal para a manutenção do indivíduo, da cultura e da sociedade. Uma das razões para explicar a adoção do parâmetro de sensações de prazer e de dor, é que esses são originários das experiências corpóreas da pessoa durante as relações sociais e as relações com o ambiente. Sensações que se manifestam em todo corpo humano vivo.

O prazer e a dor são indicadores que podem demandar uma intervenção bioética, à medida que refletem a satisfação das necessidades dos indivíduos. Tais satisfações podem ser mensuradas pela possibilidade dos indivíduos experimentarem graus diferentes de prazer ou dor, diferença promovida pelas condições sociais e econômicas a quais estão submetidos. O método assume que é na corporeidade humana que se constata a unidade indissolúvel, material e universal experimentada entre todos da espécie humana, o corpo. Pois é através dos sentidos deste que realizamos física, sensorial e subjetivamente a existência material da vida como experiência sensóriomotora. É só no corpo, e através dele, que a experiência de plenitude da vida se manifesta, ou seja, é o corpo que nos une num substrato universal. Em qualquer cultura, independente de raça, credo, moral, ética ou qualquer outra subjetividade, é o corpo material que proporciona e dá sentindo à vida de qualquer ser humano. Sobre esse tema, Cruz e Trindade salientam:

Assim, é proposto o resgate da ideia de corpo, que transcende a limitação à dimensão fisiológica imposta pelo paradigma cartesiano, passando também a contemplar a dimensão social. As sensações de prazer e dor seriam os pólos extremos do aspecto das necessidades mais básicas das pessoas humanas, que ganham existência na experiência corpórea de cada individuo em suas relações com o meio social e com o meio ambiente" (Cruz, Trindade, 2006, p.493). 
Desta maneira, faz-se necessária a crítica a respeito da forma como vem se realizando o processo de domínio dos corpos na atualidade, em que as instituições assumem o papel de controle, físico e subjetivo, em suas micro-relações de poder, que capilarizam as relações "intercorporais" na sociedade capitalista. Desta feita, como anunciado no item anterior, quando o humano em sua corporeidade é colocado à venda, como mercadoria, suas potencialidades são apropriadas pelos detentores dos modos de produção, comprando sua força vital de trabalho. Diante deste cenário, nos resta questionar: quais são os impactos dessa exploração ao longo da vida do trabalhador, ou seja, quais são as consequências da exploração para a constituição do humano velho?

\section{O descarte da velhice e a bioética para o envelhecimento humano}

A população mundial vem passando por um processo de envelhecimento sem precedentes, que atinge todas as classes sociais. Este fenômeno já é uma realidade experimentada por diversos países centrais há muitos anos; já nos países ditos periféricos, como é o caso do Brasil, este fenômeno vem ganhando força nas últimas décadas.

Teixeira (2008) se debruçou sobre o tema do envelhecimento da população e apontou que este fenômeno tem sua causa no aumento da expectativa de vida, no declínio da taxa de fecundidade, no avanço médico científico, nos programas de esterilização em massa nas regiões periféricas e nas altas taxas de mortalidade da população jovem e pobre, sobretudo nos países mais desiguais. $O$ fenômeno do envelhecimento que há 50 anos se restringia ao debate da esfera privada e familiar passou a ser tratado, atualmente, como um fator importante a ser discutido também na esfera política, pública e social.

Do ponto de vista demográfico individual, o envelhecimento é definido pelos anos vividos e são considerados velhos, pela OMS, aqueles indivíduos que tem 60 anos de idade ou mais (OMS, 2015). Na dimensão biológica o envelhecimento é determinado como um processo de mudança universal, induzido geneticamente e que se manifesta com a diminuição da plasticidade corporal, no aumento da vulnerabilidade devido à decrepitude corpórea e no aumento de probabilidade de morte. Ou seja, o envelhecimento humano é caracterizado pela perda gradativa das potencialidades físicas relacionadas à corporeidade e na diminuição do papel social desse individuo, tanto no âmbito familiar, como no produtivo e econômico.

Em nossa sociedade podemos perceber que a questão do envelhecimento vem se tornando um problema social, principalmente para a classe trabalhadora, que 
só tem como propriedade sua força de trabalho e que não detém controle total sobre o seu tempo de vida - pois o mesmo foi posto à venda no mercado de trabalho. Sobre esta problemática, a autora destaca:

(...) a classe dos trabalhadores improdutivos, aqueles cuja forma de trabalho são utilizadas, como serviços, seja para uso público ou para o capitalista, entram no processo de realização da mais-mais valia, em serviços, comércio, bancos e outras modalidades contemporâneas. O capital incorpora ainda o proletariado precarizado, o subproletariado moderno, os temporários, terceirizados, precarizados em geral, e também os desempregados e todos aqueles que possuem apenas sua força de trabalho não utilizada pelo mercado formal, os expulsos do processo produtivo e do mercado de trabalho, todos aqueles que compõem a classe-quevive-do-trabalho (Teixeira, 2008, p.23).

A moral capitalista que considera "o tempo é tudo, o homem é nada" (Teixeira, 2008 , p.23) faz com que se crie uma experiência cronológica na vida dos trabalhadores com traços negativos, quando expressados no convívio social, à medida que o mesmo transforma o seu tempo de vida em tempo de trabalho, em detrimento de suas necessidades humano-genéricas. Essa expressão é ainda mais negativa para os trabalhadores que estão envelhecendo sob a realidade econômica de países que estão na periferia do capitalismo. Países estes em que condições estruturais de desigualdades e injustiças sociais são historicamente persistentes. Lugares onde a classe trabalhadora ainda se depara, nos dias de hoje, com o risco do avanço de políticas de cunho neoliberal que conspiram estratégias para o desmonte do frágil sistema de seguridade social proporcionado pelo Estado.

Políticas liberais que tem o claro objetivo de promover a pulverização dos direitos trabalhistas e previdenciários, levando ao aumento de jornada de trabalho, diminuindo as horas de descanso e estipulando um maior tempo de contribuições, fazendo com que o trabalhador envelheça trabalhando, em consonância com a lógica expansionista do capital, com sua moral de acumulação e exploração do trabalho. Nas palavras de Teixeira:

A centralidade no envelhecimento do trabalhador advém do movimento real e não apenas de pressupostos teórico-metodológicos. É a classe trabalhadora a protagonista da tragédia do envelhecimento, considerando-se a impossibilidade de reprodução social e de uma vida cheia de sentido e valor na ordem do capital, principalmente, quando perde o "valor de uso" para o capital, em função da expropriação dos meios de produção do tempo de vida. Portanto, não é para todas as classes que o envelhecimento promove efeitos imediatos de isolamento, exclusão 
das relações sociais, do espaço público, do mundo produtivo, político, artístico, dentre outras expressões fenomênicas dos processos produtores de desigualdades sociais (Teixeira, 2008, p.25).

Partindo da premissa de que o ser humano experimenta o envelhecer do seu corpo de acordo com o lugar que ele ocupa nas relações de produção e reprodução capitalista, devemos sempre questionar a ideia de que o envelhecimento é um processo universal e que se realiza de forma simétrica e igualitária para todos. "Os homens não vivem e não se reproduzem como iguais, antes, são distintos nas relações que estabelecem na produção da sua sociabilidade (Teixeira, 2008, p.25)".

Os conflitos éticos relacionados ao envelhecimento se acirram ao notar que nestes tempos vem sendo implementado um apelo ao culto do corpo. Com fins mercadológicos, vendem uma falsa ideia de juventude eterna, em que o processo de envelhecimento se torna ideologicamente um sinal de negligência individual e algo a ser prevenido/evitado. Assim, conforme analisam Almeida e Gomes (2014) os meios de comunicação e o complexo médico industrial sustentam o discurso da prevenção por meio da gestão individual de riscos à saúde por meio da divulgação de conceito sobre hábitos/estilo de vida a serem vendidos no mercado.

O crescimento da população idosa é um fenômeno mundial e no Brasil esse crescimento vem aumentando de forma acelerada. Segundo Silva e Caldas (2009), todos os anos, cerca de 650 mil novos idosos são agregados à população brasileira, sendo que grande parte desses idosos apresentam alguma doença crônica ou alguma limitação funcional. Devido ao crescimento rápido dessa parcela da população, a legislação brasileira avançou alguns passos com a promulgação, no ano de 2003, do Estatuto do Idoso. E também, no ano de 2006, por meio do SUS, formulou-se o pacto pela saúde em que o primeiro eixo contempla seis prioridades da saúde, dentre elas, a saúde integral da pessoa idosa, independente ou não.

Não é possível, entretanto, compreender o processo de velhice sem ter em mente o conceito de vulnerabilidade. De acordo com Almeida (2010), a vulnerabilidade está presente na essência de todo ser humano, um traço inerente ao humano. Segundo a autora, o termo também pode ser aplicado no reconhecimento de grupos sociais específicos, que por circunstâncias física, psíquica, social, política ou econômica, podem ser vistos como grupos vulneráveis.

$O$ aspecto fundamental para que a vulnerabilidade seja entendida como princípio ético é a obrigação da ação moral, que pode ser realizada em dois sentidos: sob uma ação mais restrita e individual e também sob uma ação mais ampla e coletiva. 
Podemos considerar ainda de acordo com Almeida (2010) também que a vulnerabilidade pode ser a perda da autonomia, quando as vontades e decisões deixam de ser consideradas. $O$ estudo de tal condição requer um olhar ético para perceber as nuances entre as pessoas sem autonomia, que por alguma razão se tornam indivíduos vulneráveis diante de uma realidade que nega a sua existência. Daí a importância de se pensar em mecanismos que visem à proteção de grupos vulneráveis. Para tanto, deve estar presente na consciência da humanidade o reconhecimento de sua própria vulnerabilidade, já que todos um dia se encontrarão em uma realidade de fragilidade inerente à vida. É preciso ir ao encontro ao outro para assim, construir uma relação mutuamente benéfica, desenvolvendo a ética necessária para a superação de nossas próprias fragilidades.

Nesse contexto, a gerontologia surge como ferramenta epistemológica para analisar os fenômenos do envelhecimento humano. Ainda de acordo com Almeida (2010), esta ciência embora seja moderna possui antiga história. Deste modo, a velhice se expressa como um fenômeno que não é estanque e natural, mas sim relativa às diversas facetas que envolvem o processo do envelhecer para além de uma dimensão puramente cronológica.

Na sociedade ocidental capitalista a vida humana é convertida em mercadoria, e nesta senda, o corpo envelhecido tende a ser descartável (assim como todas as mercadorias). Em uma sociedade produtivista em que o adulto jovem é o centro das atenções única e exclusivamente pela sua capacidade produtiva, resta à pessoa idosa uma imagem estigmatizada pela descartabilidade e/ou valorizada enquanto pequenos segmentos com poder de compra. Por isso, o debate é preciso. Preciso no sentido de realizar um chamamento sobre a necessidade de se criar estratégias educacionais, políticas e sociais, preparar a sociedade para o fenômeno do envelhecimento populacional, melhorando a atenção à saúde de todos os idosos e se preocupando com o número cada vez maior dessa parcela da população que tende a crescer ainda mais com o passar dos anos.

Diante do cenário de conflitos crescentes envolvendo esta etapa da vida humana, a bioética pode se tornar a ética do mundo que envelhece. Pois o envelhecimento rápido e sem equilíbrio da humanidade pode levar a um grande colapso econômico. Para Almeida (2010) essa realidade torna a reflexão bioética uma importante ferramenta para a sobrevivência da humanidade.

Uma bioética para o envelhecimento, mais especificamente, deve contribuir com a criação de políticas públicas que permitam enfrentar as reais necessidades da po- 
pulação idosa. Isto é, com objetivo de se tornar uma ética social, uma bioética para o envelhecimento que reconheça os idosos como parte integrante da sociedade.

Podemos destacar essa relação entre a bioética do envelhecimento e todas as suas peculiaridades com os aspectos éticos que permeiam as relações e os conflitos entre o trabalhador e o capital durante a vida produtiva a partir da análise de autores como Berlinguer (1993) e Garrafa e Porto (2002), especificamente quando estes autores apontam como a materialidade das relações de trabalho, no caso do primeiro do autor, e a corporeidade, no caso dos segundos, podem nos servir de parâmetro para a reflexão bioética, pois é no corpo, e mais evidente no corpo envelhecido do trabalhador, que estão presentes todas as marcas concretas e subjetivas deixadas pela exploração e pelo controle exercido pelo capital, o que, em muitos casos, promove a perda da dignidade, da autonomia e da liberdade quando colocado à venda no mercado em troca de meios mínimos de subsistência.

Quando a corporeidade já não responde mais às demandas do mercado e da produção, por motivos de doenças ou pela decrepitude biológica relacionada à velhice, em que a força de trabalho presente na corporeidade não puder corresponder mais às demandas produtivas exigidas pelo capital, esse corpo envelhecido é descartado. Diante desse contexto, a bioética do envelhecimento reconhece o velho como individuo biográfico, de história única, que deve ser reconhecido e ter seus direitos como cidadãos assegurados. A cidadania da população idosa deve contar com espaços de participação em que o idoso seja parte constituinte, tendo seus valores morais e éticos, ou seja, sua humanidade respeitada e levada em consideração nas decisões da comunidade humana.

\section{Considerações finais}

Ao longo deste trabalho tentamos demonstrar, por meio da pluralidade teórica proporcionada pela bioética e outras áreas do saber, como as relações sociais de produção estão diretamente relacionadas ao controle e exploração dos corpos. A força de trabalho contida na corporeidade humana é posta a venda como mercadoria e, como toda mercadoria, é descartada quando este corpo esgotado pela exploração não corresponder mais às demandas físicas e subjetivas impostas pela produção. Consideramos a percepção bioética de suma importância para a análise dos conflitos persistentes na relação dos trabalhadores com o capital, mais especificamente dos trabalhadores velhos que se encontram em condições de vulnerabilidade física e social, trabalhadores estes que não correspondem ao público de consumo, ou seja, à parcela de idosos privilegiados economicamente. 
Desta feita, temos que a vida na velhice é condicionada pelo lugar que esse indivíduo ocupou ao longo de sua vida e ocupa na teia de relações sociais. Decorre disso que o reconhecimento ético da humanidade e da vulnerabilidade do indivíduo envelhecido implica em reconhecê-lo como trabalhador explorado pelo capital. Assim, concluímos que a população idosa, que apresenta crescimento vertiginoso, requer um olhar humanizado e ético que transcenda $\urcorner$ a descartabilidade do corpo em sua expressão mercadológica. A bioética é um importante instrumento de discussão, promoção e intervenção que pode proporcionar o despertar desse reconhecimento. Respeitar a velhice em sua totalidade significa conceber o humano para além de sua expressão como mercadoria na sociedade contemporânea.

\section{Referências}

1. Alban M. Automação Flexivel: O caso do Taylorismo-Fordismo e a Supremacia do Toyotismo.Revista O \& S 1999. 6(15): 71-82.

2. Almeida, $L D$. Suscetibilidade: novo sentido para a vulnerabilidade. Revista Bioética 2010; 18(3): 537 - 48.

3. Almeida MR, Gomes RM. Medicalização social e educação: contribuições da teoria da determinação social do processo saúdedoença. Nuances: estudos sobre Educação 2014; 25 (1): 155-75.

4. Berlinguer $\mathrm{G}$. A relação entre saúde e trabalho do ponto de vista bioético. Saúde soc 1993; 2(2): 101-34.

5. Da Cruz MR, Trindade ES. Bioética de Intervenção - uma proposta epistemológica e uma necessidade para sociedades com grupos sociais vulneráveis. Revista Brasileira de Bioética 2006; (2) 4: 483-500.

6. Fiori JL. Os moedeiros falsos. Rio de Janeiro: EditoraVozes, 1997.

7. Garrafa V. Inclusão social no contexto político da Bioética. Revista Brasileira de Bioética 2005; (1)2: 122-32.

8. Garrafa V. Da bioética de princípios a uma bioética interventiva. Revista Bioética 2005; (13)1: 125-34.

9. Garrafa V, Porto $D$. Intervention bioethics: a proposal for peripheral countries in a context of power and injustice.. Bioethics. 2003 Oct; $17(5-6): 399-416$. 
10.Lacaz FAC. Qualidade de vida no trabalho e saúde/doença. C \& $S$ Col 2000;5(1):151-61.

11.Leontiev AN. Actividad, conciencia y personalidad. Buenos Aires: Ediciones Ciencias Del Hombre, 1978.

12.Lins TA, Vasconcelos LCF, Palacios M. Bioética e saúde do trabalhador: uma interface. Revista Bioética 2015; 23 (2): 293-303.

13. Marx K. O capital: crítica da economia política. São Paulo: Boitempo, 2015.

14. Nascimento WF, Garrafa, V. Por uma vida não colonizada: diálogo entre bioética de intervenção e colonialidade. Revista Saúde e Sociedade 2011; (20)2: p. 287-99.

15. OMS - Organização Mundial da Saúde. Definition of an older or elderly person. World Health Organization, Genebra; 2015

16. Porto D, Garrafa V. Bioética de intervenção: considerações sobre economia de mercado. Revista de Bioética 2005; (13)1: $p$. 2835-43.

17. Santos VC. Da era fordista ao desemprego estrutural da força de trabalho: mudanças na organização da produção e do trabaIho e seus reflexos. In:VI Colóquio Internacional Marx e Engels. Campinas, Brasil;2009: 1-9.

18. Silva GC, Caldas CP. Aspectos éticos da abordagem contemporânea do envelhecimento. Revista ArqCiênc Saúde 2009;16(2):76-82.

19. Teixeira S. Envelhecimento e Trabalho no Tempo do Capital: Implicações para a proteção social no Brasil. São Paulo: Cortez; 2008. 